\title{
Clinico-Demographic Profile and Pregnancy Outcome in Placenta Previa: A Study from Tertiary Care Hospital
}

\author{
Haque $\mathrm{H}^{1}$ Pandit $\mathrm{U}^{2}$
}

\begin{abstract}
Introduction: Placenta previa is an obstetric complication which causes considerable maternal and fetal morbidity and mortality during pregnancy. This study is done with the objective to find out the clinico-demographic factors associated with placenta previa and to analyze maternal and perinatal outcome in these cases. Methods: This was a retrospective study done in the department of Obstetrics and Gynecology of Nepalgunj Medical College Teaching Hospital, Nepalgunj, a tertiary care hospital from Midwestern Nepal. Relevant data were retrieved from maternity register from June 2015 to May 2017. All women who had undergone caesarean section for placenta previa were included in this study. Result: Out of total 5812 deliveries during the study period there were 50 caesarian sections done for placenta previa which is $0.86 \%$ of total deliveries. Maximum number of mothers belonged to $26-30$ years of age group. Commonest type of placenta previa was minor type. About $72 \%$ were multiparous. $20 \%$ had previous LSCS and $24 \%$ had previous abortion. Postpartum hemorrhage was present in $36 \%$ mothers and $32 \%$ received blood transfusion. About $64 \%$ new born were preterm and low birth weight. $34 \%$ babies had less than 7 apgar score at $5 \mathrm{~min}$. Still births were $6 \%$. Conclusion: Placenta previa poses greater risk and need of blood transfusion to mother as well as birth of preterm and low birth weight babies which leads to perinatal morbidity and mortality. Timely diagnosis, regular antenatal check up and effective management may improve pregnancy outcome.
\end{abstract}

Key words: Profile, pregnancy outcome, placenta previa, Nepalgunj medical college

\section{INTRODUCTION}

Placenta previa is an obstetric complication which causes considerable maternal and fetal morbidity and mortality during pregnancy ${ }^{1}$. When the placenta is inserted wholly or partially in the lower uterine segment it is termed as placenta previa. The incidence is approximately 4-5 per 1000 pregnancies ${ }^{2,3}$. About one-third cases of antepartum hemorrhage belong to placenta previa ${ }^{4}$. For clinical purpose, placenta previa is graded into major and minor types. If the placenta lies over the cervical os it is considered as a major previa, else it is a minor previa ${ }^{5}$. Advancing maternal age, multiparity, previous Cesarean delivery, abortion and male fetuses all conferred increased risk for placenta previa ${ }^{3}$. Pregnancies complicated with placenta previa had significantly higher rates of second-trimester bleeding, pathological presentations, abruptio placentae, congenital malformations, perinatal mortality, Cesarean delivery, Apgar scores at $5 \mathrm{~min}$ lower than 7, postpartum hemorrhage, postpartum anemia and increased hospital stay as compared to pregnancies without placenta pravia ${ }^{6}$. Present study was to find out the clinico-demographic factors associated with placenta previa and to determine maternal and perinatal outcome.

1. Dr. Husneyara Haque

2. Dr. Upendra Pandit

Address for correspondence:

Dr. Husneyara Haque

Department of Obst. \& Gynae.

Nepalgunj Medical College \& Teaching Hospital

Nepalgunj, Banke, Nepal

Email: haqhusna@gmail.com

\section{MATERIAL AND METHODS}

This is a retrospective study done in the department of Obstetrics and Gynecology, Nepalgunj Medical College Teaching Hospital, Nepalgunj, a tertiary care hospital from Midwestern Nepal. Relevant data were collected from maternity register for the period of two years from June 2015 to May 2017. Approval for the study was taken from department. Study population was 50 mothers. All women who had undergone caesarean section for placenta previa were included in this study. Relevant clinico-demographic data were collected and maternal and neonatal outcome were observed, tabulated, analysed and presented in percentage.

\section{RESULT}

During the two year period there were 5812 deliveries, out of them 1692 were undergone caesarian section. Among them, caesarean section done for placenta previa was 50 , which is 0.86 percent of total deliveries. Table I shows $16(32 \%)$ belonged to $26-30$ years of age group followed by 15 (30\%) to 21- 25 years age group and $12(24 \%)$ to $31-35$ years of age group. Four (8\%) women were more than 35 years of age.

\begin{tabular}{|c|c|c|}
\hline Age group (yrs) & $\mathbf{N = 5 0}$ & Frequency (\%) \\
\hline$<20$ & 3 & 6 \\
\hline $21-25$ & 15 & 30 \\
\hline $26-30$ & 16 & 32 \\
\hline $31-35$ & 12 & 24 \\
\hline$>35$ & 4 & 8 \\
\hline Total & $\mathbf{5 0}$ & $\mathbf{1 0 0}$ \\
\hline
\end{tabular}

Table I: Distribution of mothers according to age group 


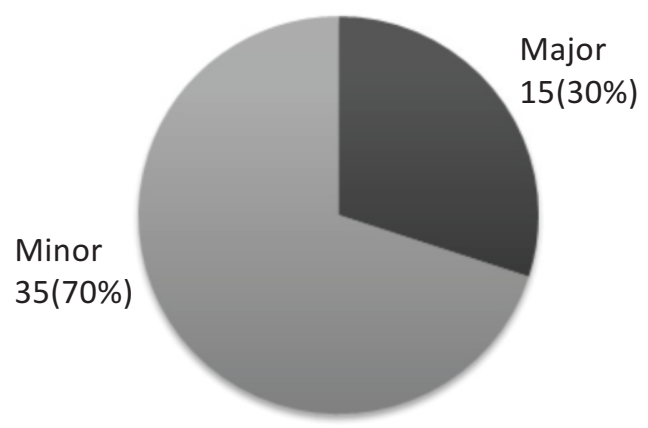

Figure 1 shows type of placenta previa.

\begin{tabular}{|l|c|c|c|}
\hline Obstetric profile & N=50 & Frequency (\%) \\
\hline \multirow{2}{*}{ Parity } & Primi & 14 & 28 \\
\cline { 2 - 4 } & Multi & 36 & 72 \\
\hline Previous LSCS & 11 & 22 \\
\hline Previous abortion & 12 & 24 \\
\hline Malpresentation & 10 & 20 \\
\hline $\begin{array}{l}\text { Placental abnormality } \\
\text { (morbid adherent placenta) }\end{array}$ & 1 & 2 \\
\hline No other associated factors & 16 & 32 \\
\hline
\end{tabular}

Table II: Obstetric profile of subjects

\begin{tabular}{|l|c|c|}
\hline Factors & $\mathbf{N = 5 0}$ & Frequency (\%) \\
\hline Postpartum Hemorrhage & 18 & 36 \\
\hline Blood transfusion & 16 & 32 \\
\hline No complication & 16 & 32 \\
\hline
\end{tabular}

Table III: Obstetrical complications

\begin{tabular}{|c|c|c|c|}
\hline \multicolumn{2}{|l|}{ Factors } & $N=50$ & Frequency (\%) \\
\hline \multirow{3}{*}{$\begin{array}{c}\text { Gestational age } \\
\text { (weeks) }\end{array}$} & $28-33$ & 13 & 26 \\
\hline & $34-36$ & 19 & 38 \\
\hline & $>37$ & 18 & 36 \\
\hline Preterm birth & & 32 & 64 \\
\hline \multirow{4}{*}{$\begin{array}{l}\text { Baby weight } \\
\text { (gms) }\end{array}$} & $<1500$ & 3 & 6 \\
\hline & $1500-2499$ & 29 & 58 \\
\hline & $2500-3500$ & 14 & 28 \\
\hline & $>3500$ & 4 & 8 \\
\hline \multicolumn{2}{|c|}{ Low birth weight babies } & 32 & 64 \\
\hline \multicolumn{2}{|c|}{ Apgar score ( $<7$ in 5 minutes) } & 17 & 34 \\
\hline \multicolumn{2}{|c|}{ Apgar score (>7 in 5 minutes) } & 30 & 60 \\
\hline \multicolumn{2}{|c|}{ Still birth (Apgar score 0) } & 3 & 6 \\
\hline \multicolumn{2}{|c|}{ Male baby } & 29 & 58 \\
\hline \multicolumn{2}{|l|}{ Female baby } & 21 & 42 \\
\hline
\end{tabular}

Table IV: Neonatal outcome
Out of 50 participants, $15(30 \%)$ constituted major type while 35 (70\%) were minor type. Majority of women i.e. $36(72 \%)$ were multi para. $11(22 \%)$ were undergone previous LSCS and $12(24 \%)$ had history of previous abortion. Malpresentation was present in $10(20 \%)$ subjects. One woman had morbid adherent placenta. $18(36 \%)$ cases of placenta previa were complicated by postpartum hemorrhage and $16(32 \%)$ women were given blood transfusion. No maternal mortality observed from placenta previa.

Table IV shows neonatal outcome. About 32(64\%) babies were preterm and same numbers of babies were low birth weight. In $17(34 \%)$ babies, apgar score in 5 minute was less than 7 . The still birth deliveries were $3(6 \%)$. Male baby outnumbered female baby, $29(58 \%)$ of all deliveries.

\section{DISCUSSION}

Placenta previa invites serious complications during pregnancy which is associated with increased maternal and perinatal morbidity and mortality.

In this study out of total 5812 deliveries, $0.86 \%$ cases were undergone caesarian section for placenta previa. This finding is slightly higher than the result obtained by Ojha N. who did similar study at TUTH, Kathmandu and found that $0.55 \%$ of caesarian sections were done for placenta previa ${ }^{7}$. This finding could be due to the reason that Nepalgunj medical college hospital is a major tertiary referral centre in mid western and far western region. High risk cases are usually referred from various district hospitals of the region. In the meta analysis reviewing studies on placenta previa between 1950-1996, among 13,992 patients diagnosed with placenta previa, the reported incidence of placenta previa ranged from $0.28 \%$ $2.0 \%{ }^{8}$. This is similar with our observation. In this study, almost $1 / 3$ rd of subjects were more than 30 years of age and similar number belonged to $26-30$ years age group. This finding is similar with the finding obtained by Ojha $\mathrm{N}^{7}$. Minor type of placenta previa was the most common diagnosis in this study which is also similar to same study ${ }^{7}$.

Study reveals that placenta previa was more common in multiparous women i.e. in $72 \%$ of cases. Various studies have shown that multi parity is an important risk factor for placenta previa ${ }^{9,10}$. Similar finding was reported in the study done by Lama S. et.al. ${ }^{11}$ Findings suggest that $22 \%$ of participants were undergone previous LSCS and $24 \%$ had history of previous abortion. Study done by Ananth CV et al. shows a strong association between a previous cesarean delivery, spontaneous or induced abortion, and the subsequent development of placenta previa ${ }^{8}$. In a different study done by A.S Anzaku et.al. in 135 cases of placenta praevia among 10,895 deliveries found previous history of caesarean section in $40.7 \%$ and previous history of abortion in $20.4 \%{ }^{12}$. 
This study indicates 18 (36\%) cases of placenta previa were complicated by postpartum hemorrhage and 16 (32\%) women were given blood transfusion. Similar result was observed in the study done by Ojha N ${ }^{7}$. In a A Systematic Review and MetaAnalysis by Dazhi Fan et.al, who draw result from 1148 studies, 11 included in the meta-analysis, which involved 5146 unique pregnant women with placenta previa found that overall pooled incidence of $\mathrm{PPH}$ was $22.3 \%{ }^{13}$.

Regarding neonatal outcome, Infants born to women with placenta previa had significant number of low birth weight, prematurity, Apgar scores of $<7$ at $5 \mathrm{~min}$. and stillbirth. This observation is consistent with previous studies ${ }^{7,14,15}$. The possible explanation for these could be that the bleeding associated with placenta previa may lead to hypoxia, intrauterine growth restriction, and prematurity with underdeveloped organ systems. There was slight preponderance of male babies in our study. This finding is consistent with the study done by Wen SW et $\mathrm{al}^{16}$.

\section{CONCLUSION}

Placenta previa is one of the main indications for caesarian sections. Grand multiparty mother has got more risk to have abnormal placentation. Placenta previa also commonly invites complications like post partum hemorrhage followed by blood transfusion. So that early detection of placentation by ultrasound and timeliness intervention prevents the maternal and perinatal morbidity and mortality.

\section{REFERENCES}

1. Elizabeth Eliet Senkoro et.al. Frequency, Risk Factors, and Adverse Fetomaternal Outcomes of Placenta Previa in Northern Tanzania. Journal of Pregnancy 2017, Article ID 5936309, 7 pages.

2. Bhide A, Thilaganathan B. Recent advances in the management of placenta previa. Curr Opin Obstet Gynecol 2004 Dec; 16(6):447-51.

3. Faiz AS, Ananth CV. Etiology and risk factors for placenta previa: an overview and meta-analysis of observational studies. J Matern Featal Neonatal Med. 2003 Mar: 13(3):175-90.

4. Dutta DC (2006) Antepartum hemorrhage. In: Konar HL (Ed.), Textbook of obstetrics. (6th edn), New central book agency, Kolkata, India, pp. 243-246.

5. Royal College of Obstetricians and Gynaecologists: Placenta previa and placenta previa accrete: Diagnosis and management. Guideline no. 27, October 2005.

6. Sheiner E, Shoham-Vardi I, Hallak M, Hershkowitz R, Katz M, Mazor M.Placenta Previa: obstetric risk factors and pregnancy outcome. The Journal of Maternal-Fetal and Neonatal Medicine 2001;10(6):414-19.

7. Ojha N. Obstetric factors and pregnancy outcome in placenta previa. Journal of Institute of Medicine, August, 2012; 34:2:3841.

8. Ananth CV, Smulian JC, Vintzileos AM. The association of placneta previa with history of cesarean delivery and abortion:A metaanalysis. AJOG 1997;177(5):1071-78.

9. Babinszki $A$, Kerenyi $T$, Torok $O$, et al. Perinatal outcome in grand and great-grand multiparity:Effects of parity on obstetric risk factors. Am J Obstet Gynecol 1999;181:669.

10. Gilliam M, Rosenberg D, Davis F. The likelihood of placenta previa with greater number of cesarean delivery and higher parity. Obstet Gynecol2002;99(6): :976-80.

11. Lama S, Ranjit S. Study on maternal and immediate fetal outcome of placenta previa, NJOG 2016 Jul-Dec, 22(2):24-27.

12. A.S Anzaku, J Musa. Placenta Praevia: Incidence, Risk Factors, Maternal And Fetal Outcomes In A Nigerian Teaching Hospital. Jos Journal of Medicine, 2010; 6( 1): 42-46.

13. Dazhi Fan, Qing Xia, Li Liu, Shuzhen Wu, Guo Tian, Wen Wang, Song $\mathrm{Wu}$, Xiaoling Guo, andmZhengping Liu. The Incidence of Postpartum Hemorrhage in Pregnant Women with Placenta Previa: A Systematic Review and Meta-Analysis. PLoS One. 2017; 12(1): e0170194.

14. P. C. Bhutia, T. Lertbunnaphong, T. Wongwananuruk, and D. Boriboonhirunsarn, "Prevalence of pregnancy with placenta previa in Siriraj hospital," Siriraj Medical Journal, vol. 63, pp. 191-195, 2011.

15. M. Raees, Z. Parveen, and M. Kamal, "Fetal and maternal outcome in major degree placenta previa," Gomal Journal of Medical Sciences, vol. 13, no. 3, pp. 13-16, 2015.

16. Wen SW, Demissie K, Liu S, Marcoux S, Kramer MS. Placenta praevia and male sex at birth: results from a population-based study. Paediatr Perinat Epidemiol. 2000 Oct;14(4):300-4. 